\title{
Effect of Molecular Weight and Molecular Distribution on Skin Structure and Shear Strength Distribution near the Surface of Thin-Wall Injection Molded Polypropylene
}

\author{
Keisuke Maeda1 ${ }^{1}, K_{0 j i}$ Yamada $^{2}$, Kazushi Yamada1 ${ }^{*}$, Masaya Kotaki ${ }^{3,4}$, Hiroyuki Nishimura1 \\ ${ }^{1}$ Department of Advanced Fibro-Science, Kyoto Institute of Technology, Kyoto, Japan \\ ${ }^{2}$ Osaka Municipal Technical Research Institute, Osaka, Japan \\ ${ }^{3}$ Center for Fiber and Textile Science, Kyoto Institute of Technology, Kyoto, Japan \\ ${ }^{4}$ Kaneka US Material Research Center, Kaneka Americas Holding, Inc., College Station, TX, USA \\ Email: *kazushi@kit.ac.jp
}

Received 8 October 2015; accepted 4 January 2016; published 7 January 2016

Copyright (C) 2016 by authors and Scientific Research Publishing Inc.

This work is licensed under the Creative Commons Attribution International License (CC BY).

http://creativecommons.org/licenses/by/4.0/

(c) (i) Open Access

\begin{abstract}
In this study, the relationship between skin structure and shear strength distribution of thin-wall injection molded polypropylene (PP) molded at different molecular weight and molecular distribution was investigated. Skin-core structure, cross-sectional morphology, crystallinity, crystal orientation, crystal morphology and molecular orientation were evaluated by using polarized optical microscope, differential scanning calorimeter, X-ray spectroscopic analyzer and laser Raman spectroscopy, respectively, while the shear strength distribution was investigated using a micro cutting method called SAICAS (Surface And Interfacial Cutting Analysis System). The results indicated that the difference of molecular weight and molecular weight distribution showed own skin layer thickness. Especially, high molecular weight sample showed thicker layer of the lamellar orientation and molecular orientation than low molecular weight sample. In addition, wide molecular distribution sample showed large crystal orientation layer.
\end{abstract}

\section{Keywords}

Polypropylene, Thin-Wall Injection Molding, Molecular Weight and Molecular Weight Distribution, Skin-Core Structure, Shear Strength Distribution

"Corresponding author.

How to cite this paper: Maeda, K., Yamada, K., Yamada, K., Kotaki, M. and Nishimura, H. (2016) Effect of Molecular Weight and Molecular Distribution on Skin Structure and Shear Strength Distribution near the Surface of Thin-Wall Injection Molded Polypropylene. Open Journal of Organic Polymer Materials, 6, 1-10. http://dx.doi.org/10.4236/ojopm.2016.61001 


\section{Introduction}

Injection molding is one of the most used methods to make plastic products. The parts made by this technique were used in various situations such as transportation equipment, electric appliance, and supplies. Recently, light-weighting is very important thing because their weight saving causes low emission of carbon dioxide, convenience and economy. One of the simple ways to light-weighting is thin-wall injection molding. However, the resin was rapidly cooled by mold, so that the skin and core layer of molding article formed different structure and this structure influenced bulk property strongly [1]-[6]. This heterogeneous structure which is called skin-core structure was formed even if it was a thin-wall, so it is very important to understand the relationship between internal structure and property. In recent researches, effect of $\beta$ phase crystalline nucleating agent added polypropylene (PP) [7] and influence of ultra-high speed injection molding [8] were studied to reveal the relationship between non-uniform structure and property of thin-wall injection molding products. Moreover, this non-uniform structure-property relationship was also investigated in composite material [9] and non-olefin resin based materials [10]. Nevertheless, molecular weight and molecular weight distribution effects on structureproperty relationship of thick-wall materials were well studied [11]-[13]. Comparably, it has not been reported in the case of thin-wall injection molding products. Besides, a number of reports about injection molding products in various conditions but almost reports focused on only internal structure or property. Especially in property measurement, most researchers focused on the properties of entire cross-section in injection molding product. However, property distribution which has the strong relationship with skin-core structure has not been hard studied except hardness and scratch resistance property of surface [14]-[18]. In this paper, the relationship between skin-core structure and property distribution of thin-wall injection molded polypropylene with different molecular weight and molecular weight distribution was investigated. The skin-core structures were characterized in terms of morphology, crystallinity, crystal phase, lamellar and molecular orientation by using optical microscope, differential scanning calorimeter, laser Raman spectroscopy, small angle X-ray scatting and wide angle X-ray diffraction. The property distribution of shear strength was measured by micro cutting machine.

\section{Experimental}

\subsection{Materials \& Injection Molding Condition}

In this study, 4 different homo-PP resins were used. The molecular characteristics were summarized in Table 1. These resins had different molecular weight and distribution. In Table 1, there are 4 types PP resins were expressed by using 2 characters. $\mathrm{H}$ and $\mathrm{L}$ describe higher and lower molecular weight respectively. $\mathrm{N}, \mathrm{M}$ and $\mathrm{W}$ describe narrow, middle and wide molecular weight distribution respectively. Thin-wall specimen was prepared by injection molding. Resin temperature and mold temperature were controlled $240^{\circ} \mathrm{C}$ and $40^{\circ} \mathrm{C}$. Injection speed and pressure were controlled $100 \mathrm{~mm} / \mathrm{s}$ and $30 \mathrm{MPa}$. Figure 1 showed the schematic drawing of specimen. The specimen dimension is $100 \times 20 \times 1 \mathrm{~mm}$.

\subsection{Structure Analysis}

\subsubsection{POM Observation}

To observe the skin-core morphology, polarized optical microscope (POM) observation was conducted using BX-51 (Olympus Corp.) with $530 \mathrm{~nm}$ sensitive color plate. The observed cross section was FD-ND cross section (FD: Flow direction, ND: Normal direction). The samples were thin-sectioned with approximately $50 \mu \mathrm{m}$ thickness. The thin-sections were observed under cross-nicol with $-45^{\circ}$ rotated against beam line.

Table 1. Molecular characteristics of PP resins.

\begin{tabular}{ccccc}
\hline & $\mathrm{M}_{\mathrm{w}}\left(\times 10^{4}\right)$ & $\mathrm{M}_{\mathrm{n}}\left(\times 10^{4}\right)$ & $\mathrm{MWD}\left(\mathrm{M}_{\mathrm{w}} / \mathrm{M}_{\mathrm{n}}\right)$ & $\mathrm{MFR}(\mathrm{g} / 10 \mathrm{~min})$ \\
\hline $\mathrm{LN}$ & 19 & 6.4 & 3.0 & 9.0 \\
$\mathrm{LM}$ & 19 & 3.5 & 5.4 & 21 \\
$\mathrm{HM}$ & 40 & 7.4 & 5.4 & 1.9 \\
$\mathrm{HW}$ & 41 & 4.2 & 9.8 & 5.0 \\
\hline
\end{tabular}




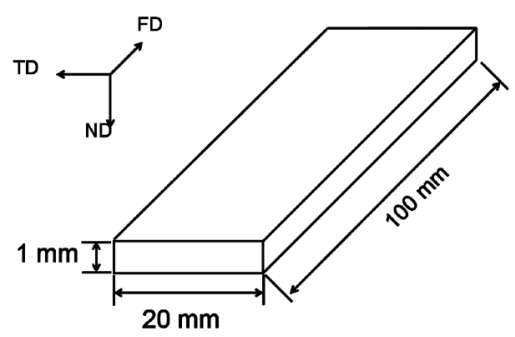

Figure 1. Schematic drawing of thin-wall PP specimen.

\subsubsection{Differential Scanning Calorimeter (DSC)}

Crystallinity was measured by using DSC (PerkinElmer, Inc. Type: DSC2920). The samples were sliced into 50 $\mu \mathrm{m}$ films from the surface to the core layer in $250 \mu \mathrm{m}$ depth to investigate the difference of crystallinity between the surface and the core layers. The samples were heated at a scanning rate of $10^{\circ} \mathrm{C} / \mathrm{min}$ from $30^{\circ} \mathrm{C}$ to $200^{\circ} \mathrm{C}$ under a nitrogen atmosphere. Crystallinity was calculated by using the following equation and crystal melt enthalpy of PP $\left(\Delta H_{m}\right)$ was used as $209 \mathrm{~J} / \mathrm{g}$ [19] (see Equation (1)).

$$
\text { Crystallinity }(\%)=\frac{\Delta H_{m}}{209} \times 100
$$

where $\Delta H_{m}$ is crystal heat fusion value of PP.

\subsubsection{Small Angle X-Ray Scatting (SAXS) and Wide Angle X-Ray Diffraction (WAXD)}

To investigate the difference of crystal morphology, i.e. lamellar orientation were measured by using SAXS (Rigaku Corp., Model: MicroMax-007HF) and $\beta$ crystalline fraction was measured by using WAXD (Rigaku Corp., Model: 55R4206). The samples were prepared by the same method as for DSC film samples. The film thickness was $50 \mu \mathrm{m}$ sliced from the surface to the core in $500 \mu \mathrm{m}$ depth for SAXS and $250 \mu \mathrm{m}$ depth for WAXD. X-ray beam was permeated the film samples in the direction to TD direction. Lamellar orientation from SAXS and crystalline orientation from WAXD was calculated by using the following Equation (2) [20].

$$
\text { Crystalline Orietation }=\frac{180-\text { FWHM }}{180}
$$

where, FWHM is Full With and Half Maximum of peak area on azimuthal analyzing of 2D-SAXS and WAXD pattern. The $\beta$ crystalline fraction $K$ from WAXD was calculated by using the following Equation (3) [21].

$$
K=\frac{I_{\beta(300)}}{I_{\alpha(110)}+I_{\alpha(040)}+I_{\alpha(130)}+I_{\beta(300)}}
$$

where, $I_{\alpha(110)}, I_{\alpha(040)}, I_{\alpha(130)}$, and $I_{\beta(300)}$ are each $\alpha$ and $\beta$ crystalline peak area come from 2D-WAXD patterns.

\subsubsection{Laser Raman Spectroscopy}

To measure molecular orientation along the FD direction, laser Raman spectroscopy (HORIBA. Ltd., Type: LabRam-HR-800) was used. The measurement was conducted on the FD-ND cross section every $2 \mu \mathrm{m}$ from the surface to the core layer in $500 \mu \mathrm{m}$ depth. The $633 \mathrm{~nm}$ red laser was used and laser beam was focused at a specimen position to approximately $2 \mu \mathrm{m}$ through the half-wave plate. The molecular orientation was evaluated by using the ratio of 844 and $813 \mathrm{~cm}^{-1}$ [22].

\subsection{Shear Strength}

To measure the difference of mechanical property distribution, shear strength distribution were measured using a micro-cutting machine called SAICAS (Surface And Interfacial Cutting Analysis System, Daipla Wintes Co. Ltd., Type: DN-01). The cutting direction was conducted on the FD-ND axis from the surface to the core layer in $500 \mu \mathrm{m}$ depth. The blade was $0.5 \mathrm{~mm}$ width diamond single crystal blade. Vertical force $\left(F_{V}\right)$ and horizontal force $\left(F_{H}\right)$ were measured during cutting. The cutting speed of vertical moving (ND direction) and horizontal moving were 0.05 and $0.5 \mu \mathrm{m} / \mathrm{s}$. The shear strength $\tau_{S}$ from these vertical and horizontal forces was calculated by the following Equation (4). 


$$
\tau_{S}=\frac{F_{H}}{2 w d \cdot \cot \varphi}
$$

where, $w$ is the blade width, $d$ is the cutting depth from the surface and $\varphi$ is the shear angle defined as $\tan ^{-1}\left(F_{H} / F_{V}\right) / 2[23]$.

\section{Results}

\subsection{Internal Structure}

\subsubsection{Skin-Core Morphology}

Figure 2 shows skin-core morphology of injection molded PP with different molecular weight and molecular weight distribution observed by POM. Near the center in ND direction, every samples had similar no anisotropy morphology (core layer). However, unique morphology as compared with the core layer were observed near the surface (skin layer named characteristic morphology layer). In low molecular weight samples, LN and LM, these samples had almost same thickness characteristic morphology layer and its thickness were about $70 \mu \mathrm{m}$. On the other hand, in high molecular weight samples, HM and HW, HM had a thicker characteristic morphology layer than HW and their thickness was about 120 and $100 \mu \mathrm{m}$, respectively. In comparison between LM and HM, it was found that high molecular weight caused the increase of characteristic morphology layer thickness. Moreover, from the results of HM and HW, a wide molecular distribution caused the increase of characteristic morphology layer thickness only in the high molecular weight sample.

\subsubsection{Crystallinity}

Figure 3 shows crystallinity distribution throughout the thickness direction of the samples measured by DSC. In addition, crystallinity of non-sliced whole sample was shown in Figure 3 . This whole sample crystallinity indi-

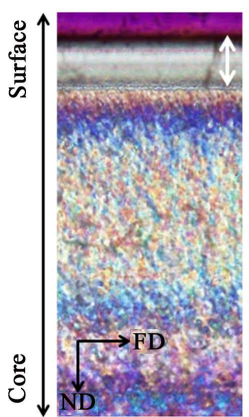

(a)

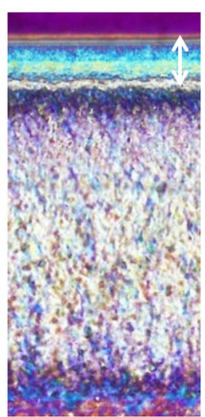

(b)

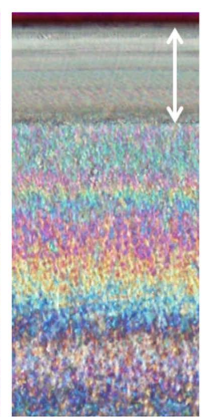

(c)

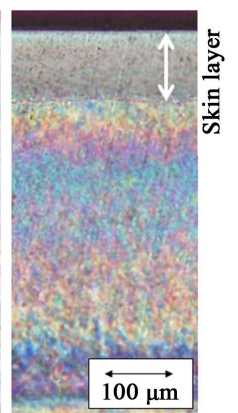

(d)

Figure 2. The morphology of cross-section on FD-ND direction by POM, (a) LN, (b) LM, (c) HM, (d) HW.

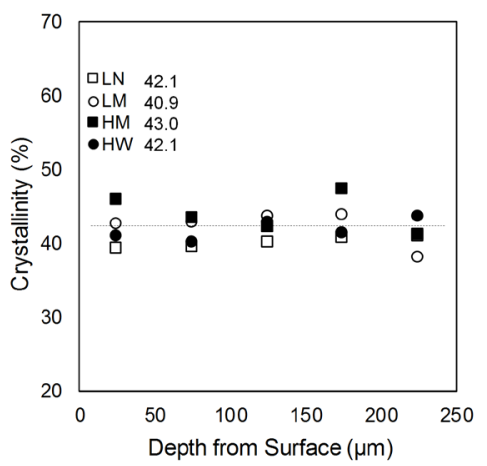

Figure 3. The results of crystallinity distribution throughout the thickness direction of the samples and crystallinity of non-sliced whole samples measured by DSC. 
cated that the molecular weight and molecular weight distribution did not significantly affect average crystallinity of the samples. From the results of DSC on sliced samples, the sample showed the characteristic crystallinity distribution was not. It indicated that the difference of molecular weight and molecular weight distribution didn't affect the crystallinity distribution.

\subsubsection{Lamellar Orientation}

Figure 4 shows 2-D SAXS patterns of thin films sliced from the surface to the core layer (0 - $500 \mu \mathrm{m})$. Lamellar orientation was clearly observed in all the samples and depth. Every samples showed strong lamellar orientation near the skin layer (lamellar oriented layer). Especially, high molecular weight sample showed strong lamellar orientation pattern on its surface. In the surface layer of HM and HW. Figure 5 shows the lamellar orientation distribution from the 2D-SAXS patterns. From this graph, it was observed that every samples had highly oriented lamellar layer near the surface (lamellar oriented layer) and the lamella orientation in the core layer was much lower than the surface layer. In low molecular weight, LN and LM had almost same lamellar orientation from the surface to the core layers. On the other hand, in high molecular weight samples, the lamellar orientation near the surface $(0-75 \mu \mathrm{m})$ and the core layer $(275-500 \mu \mathrm{m})$ were almost same, but in the middle layer $(75$ $275 \mu \mathrm{m})$, HM showed higher lamellar orientation than HW. It indicated that narrow molecular distribution caused increasing lamellar orientated layer in high molecular weight sample. As compared with LM and HM, HM showed large lamellar oriented layer.

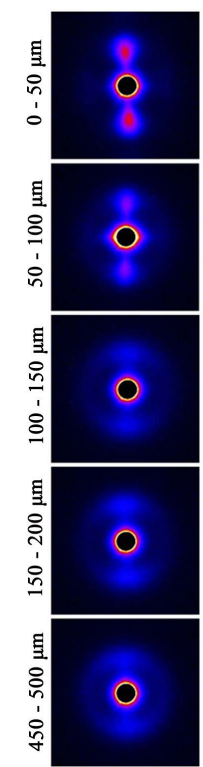

(a)
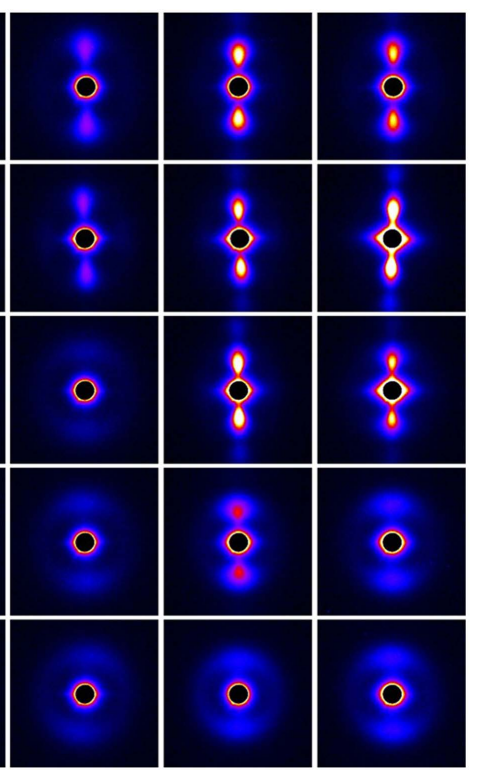

(b)

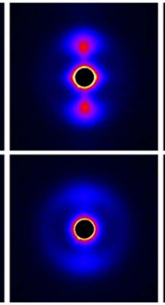

(c)

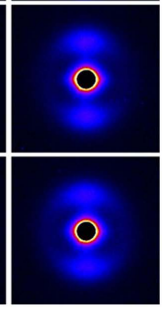

(d)

Figure 4. The 2D-SAXS patterns from the surface to core layer. (a) LN; (b) LM; (c) HM; (d) HW.

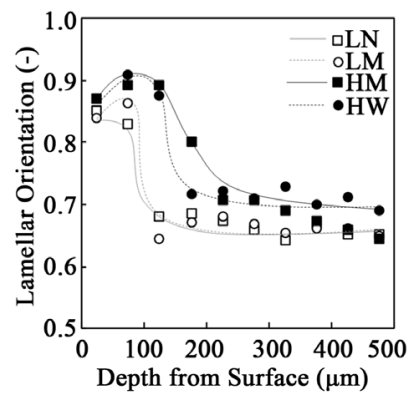

Figure 5. The lamellar orientation distribution throughout the thickness direction of the samples measured by 2D-SAXS patterns. 


\subsubsection{Crystalline Orientation and $\beta$ Crystalline Phase Fraction}

Figure 6 shows 2-D WAXD patterns of thin films sliced from the surface to core layer $(0-200 \mu \mathrm{m})$. As with 2D-SAXS pattern, every samples had high crystalline orientation layer near the surface and the crystalline orientation decreased as the depth increased. Figure 7 shows the crystalline orientation distribution from the 2D-SAXS patterns. It was observed that every samples had highly crystalline orientated layer near the surface and the crystalline orientation in core layer was lower than the surface layer. In the low molecular weight samples, LM showed highly crystalline orientated layer compared to LN. In the high molecular weight samples, HW showed highly crystalline orientated layer compared to HM. It indicated that wide molecular distribution led to high crystalline orientation near the surface. On the other hand, as compared LM and HM, these crystalline orientation were almost same from the surface to core layer, i.e. molecular weight didn't affect the crystalline orientation. Figure 8 shows $\beta$ crystalline phase fraction distribution in the sub-surface obtained from 2DWAXD patterns. In the low molecular weight samples, LN and LM, $\beta$ crystalline phase fraction were almost constant from the surface to core layer. On the other hand, HM and HW had high $\beta$ crystalline fraction layer near the surface. In other words, high molecular weight caused the increase of $\beta$ crystalline fraction.

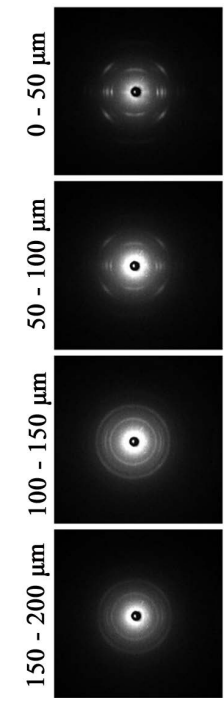

(a)

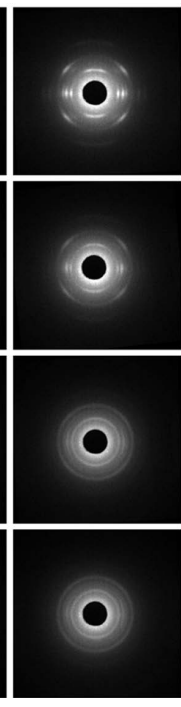

(b)

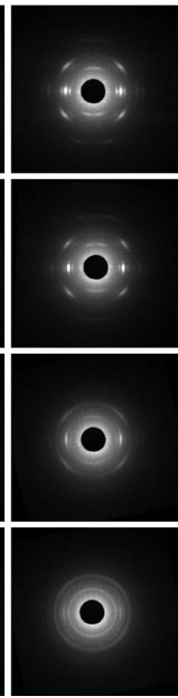

(c)

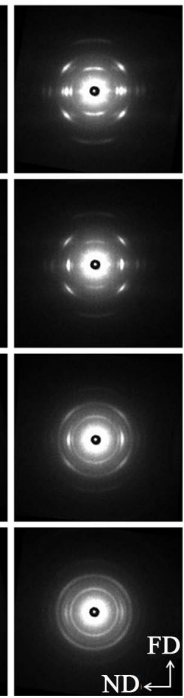

(d)

Figure 6. The 2D-WAXD patterns from the surface to depth at 250 $\mu \mathrm{m}$. (a) LN; (b) LM; (c) HM; (d) HW.

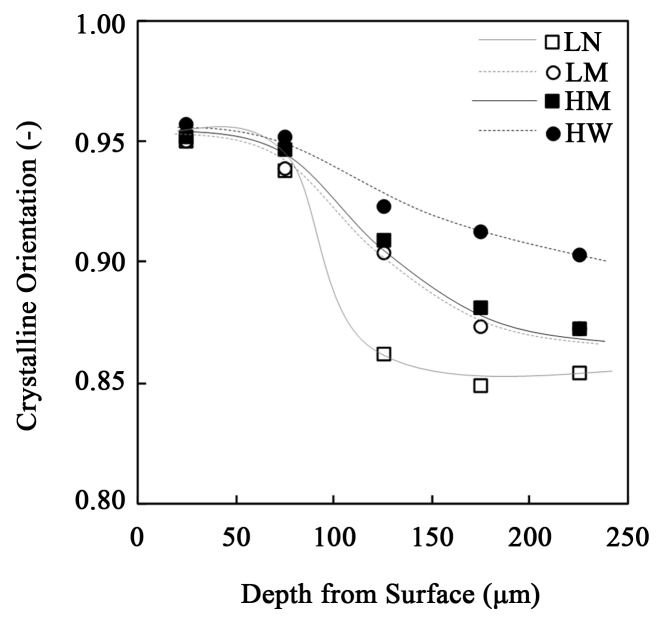

Figure 7. The crystalline orientation distribution throughout the thickness direction of the samples measured by 2D-WAXD patterns. 


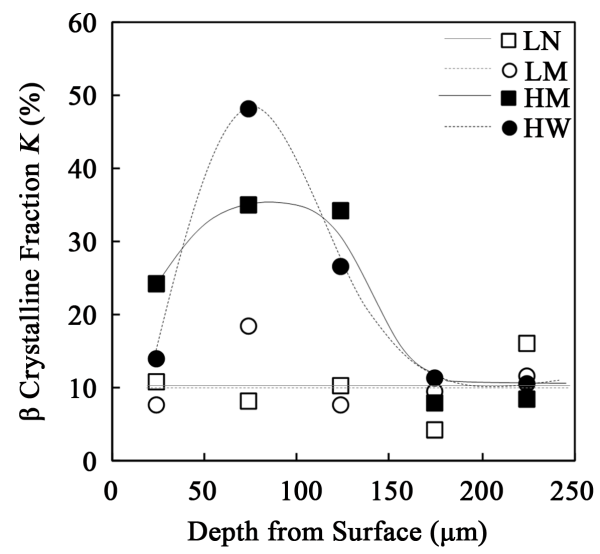

Figure 8. The $\beta$ crystalline phase fraction distribution in the subsurface obtained from 2D-WAXD patterns.

\subsubsection{Molecular Orientation}

Figure 9 shows the result of molecular orientation characterized by laser Raman spectroscopy. Molecular orientation was clearly observed in all the samples near the surface (molecular oriented layer) and every sample had almost same degree of molecular orientation in the core layer. In (c) HM and (d) HW samples, molecular oriented layers were observed near the surface and the thickness of the layer was about $190 \mu \mathrm{m}$, respectively. On the other hand, in (a) LN and (b) LM samples, these samples had different thickness of molecular oriented layer and its thickness were 90 and $40 \mu \mathrm{m}$, respectively. It indicated that increasing the thickness of molecular oriented layer affected by narrow molecular weight distribution in low molecular weight sample.

\subsection{Shear Strength}

As a mechanical property distribution, shear strength distribution from the surface to core layer were measured. Figure 10 shows the shear strength distribution of different molecular weight samples (LM and HM). Shear strength near the surface $(0-50 \mu \mathrm{m})$ showed high values in all the samples because of the initial contact between blade tip and sample surface and the cutting process initiation. HM showed higher shear strength than LM in the entire cutting process from the surface to core layer. It indicated that high molecular weight caused the high shear strength distribution. Figure 11(a) shows the relationship between shear strength and depth from the surface of samples with different molecular weight distribution. In Figure 11(a) LN and LM had almost same shear strength distribution. And from Figure 11(b), HM and HW also had almost same shear strength distribution. It indicated that molecular weight distribution did not significantly affect shear strength near the surface.

\section{Discussion}

This research investigated the relationship between molecular weight and molecular weight distribution, and skin layer thickness obtained by different characterization methods. High molecular weight and narrow molecular weight distribution samples led to thick lamellar oriented layer and characteristic morphology layer near the surface observed by POM and SAXS. However, according to the result of WAXD, wide molecular weight distribution sample showed thick crystalline oriented layer. This tendency of WAXD was different from that of POM and SAXS. It was indicated that lamellar orientation layer was not the same as crystalline orientation layer. Besides, molecular orientation analysis from laser Raman spectroscopy indicated that narrow molecular weight distribution showed thicker molecular oriented layer in low molecular weight samples. Whereas, molecular weight distribution didn't affect the molecular orientated layer thickness in high molecular weight samples. The characteristic structure (POM), lamellar orientation (SAXS), molecular orientation (laser Raman) and $\beta$ phase fraction (WAXD), were found to be the structure affected by molecular weight. Meanwhile, crystalline orientation (WAXD) was found to be dominantly affected by molecular weight distribution. On the other hand, molecular weight and molecular weight distribution did not affect crystallinity from DSC. In terms of the shear strength distribution, different molecular weight sample showed different shear strength distribution. It indicated that molecular orientation and/or lamellar orientation were the dominant causes for shear strength distribution. 

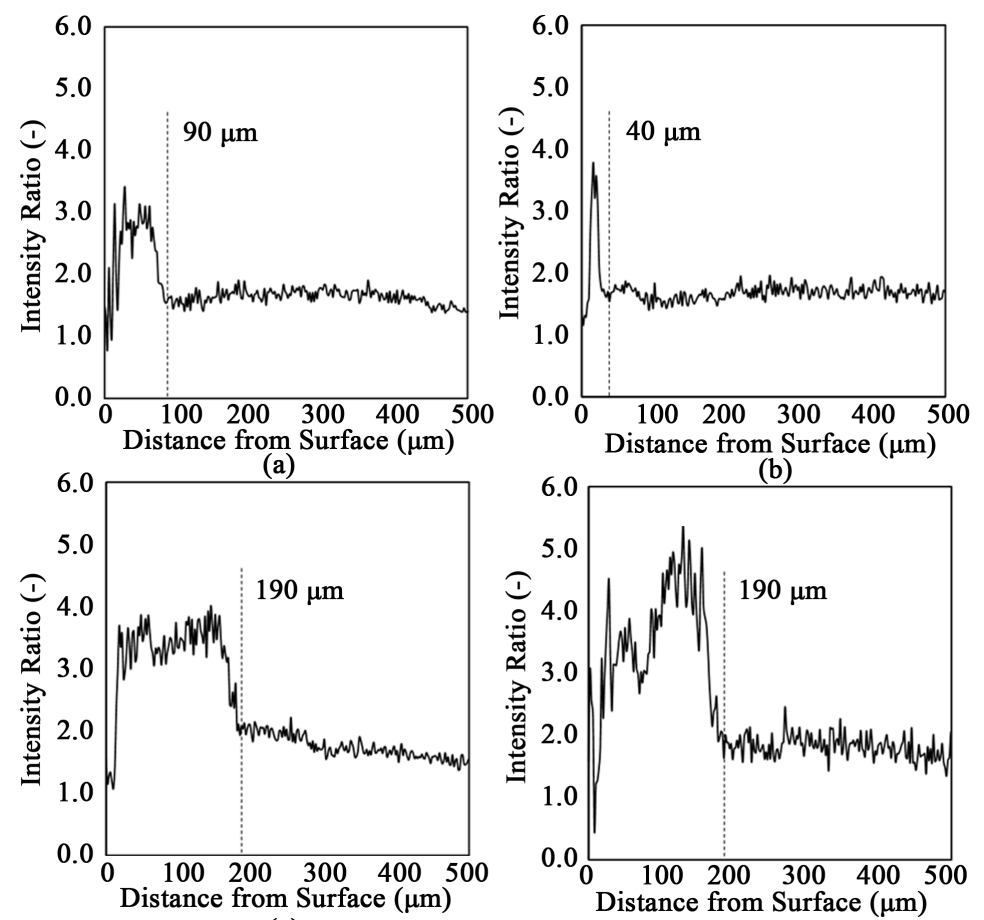

(c)

(d)

Figure 9. The intensity ratio of molecular orientation distribution among FD direction from the surface to core layer by laser Raman spectroscopy, (a) LN; (b) LM; (c) HM; (d) HW.

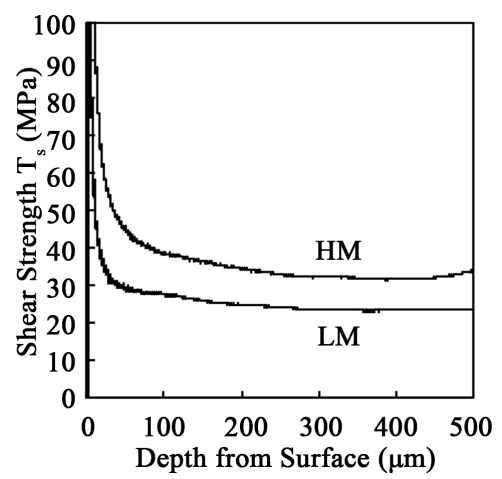

Figure 10. The shear strength distribution of LM and HM throughout the thickness direction of the samples measured by micro-cutting method.

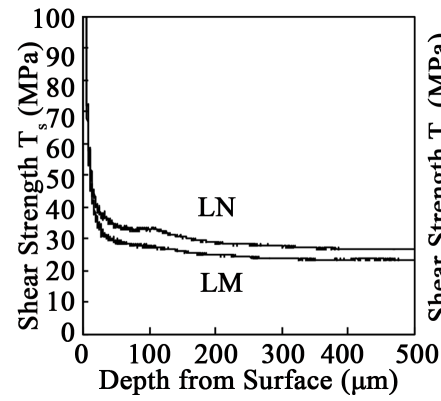

(a)

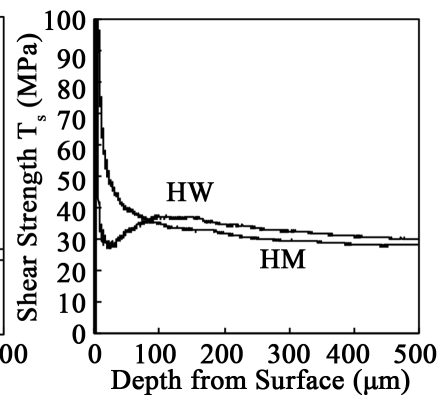

(b)

Figure 11. The shear strength distribution throughout the thickness direction of the samples, (a) LN and LM; (b) HW and HM. 


\section{Conclusion}

In this work, the relationship between skin-core structure and surface mechanical properties of thin-wall injection molded PP with different molecular weight and molecular weight distribution was investigated. High molecular weight samples showed thicker molecular oriented layer and lamellar oriented layer near the surface. The molecular weight mainly affected the lamellar orientation rather than crystalline orientation in the lamellar structure. On the other hand, molecular weight distribution affected the lamellar orientation rather than crystalline orientation. From the structure analysis and shear strength distribution measurement, the difference of lamellar orientation and/or molecular orientation was correlated to shear strength near the surface.

\section{References}

[1] Kantz, M.R., Newman, H.D. and Stigale, F.H. (1972) The Skin-Core Morphology and Structure-Property Relationships in Injection-Molded Polypropylene. Journal of Applied Polymer Science, 16, 1249-1260. http://dx.doi.org/10.1002/app.1972.070160516

[2] Fujiyama, M. and Wakino, T. (1991) Structures and Properties of Injection Moldings of Crystallization NucleatorAdded Polypropylenes. I. Structure-Property Relationships. Journal of Applied Polymer Science, 42, 2739-2747. http://dx.doi.org/10.1002/app.1991.070421012

[3] Menges, G., Wubken, G. and Horn, B. (1976) Effect of Manufacturing Conditions on Crystallinity and Morphology of Partially Crystalline Die-Casting. Colloid and Polymer Science, 254, 267-278. http://dx.doi.org/10.1007/BF01384025

[4] Trotignon, J.P., Lebrun, J.L. and Verdu, J. (1982) Crystalline Polymorphism and Orientation in Injection Molded Polypropylene. Plastics and Rubber Processing and Applications, 2, 247-251.

[5] Clark, E.S. and Spruiell, J.E. (1976) Unlimited Flex Life in the Molded-In Hinge in Polypropylene: A Structural Hypothesis. Polymer Engineering \& Science, 16, 176-181. http://dx.doi.org/10.1002/pen.760160310

[6] Ito, H., Yagisawa, Y., Saito, T., Yasuhara, T., Kikutani, T. and Yamagiwa, Y. (2005) Fundamental Study on Structure Development of Thin-Wall Injection Molded Products. Theoretical and Applied Mechanics Japan, 54, 263-268.

[7] Zhu, P.W. and Edward, G. (2004) Morphological Distribution of Injection-Moulded Isotactic Polypropylene: A Study of Synchrotron Small Angle X-Ray Scattering. Polymer, 45, 2603-2613. http://dx.doi.org/10.1016/j.polymer.2004.02.031

[8] Jiang, K., Yu, F.I., Su, R., Yang, J.F., Zhou, T., Gao, J., Deng, H., Wang, K., Zhang, Q., Chen, F. and Fu, Q. (2011) High Speed Injection Molding of High Density Polyethylene-Effects of Injection Speed on Structure and Properties. Chinese Journal of Polymer Science, 29, 456-464. http://dx.doi.org/10.1007/s10118-011-1049-3

[9] Drummer, D. and Meister, S. (2014) Correlation of Processing, Inner Structure, and Part Properties of Injection Moulded Thin-Wall Parts on Example of Polyamide 66. International Journal of Polymer Science, 2014, Article ID: 718926, 8 p.

[10] Yu, F., Deng, H., Zhang, Q., Wang, K., Zhang, C., Chen, F. and Fu, Q. (2013) Anisotropic Multilayer Conductive Networks in Carbon Nanotubes Filled Polyethylene/Polypropylene Blends Obtained through High Speed Thin Wall Injection Molding. Polymer, 54, 6425-6436. http://dx.doi.org/10.1007/s10118-011-1049-3

[11] Trotignon, J.P. and Verdu, J. (1987) Skin-Core Structure-Fatigue Behavior Relationships for Injection-Molded Parts of Polypropylene. I. Influence of Molecular Weight and Injection Conditions on the Morphology. Journal of Applied Polymer Science, 34, 1-18. http://dx.doi.org/10.1002/app.1987.070340101

[12] Fujiyama, M., Kitajima, Y. and Inata, H. (2002) Structure and Properties of Injection-Molded Polypropylenes with Different Molecular Weight Distribution and Tacticity Characteristics. Journal of Applied Polymer Science, 84, 21422156. http://dx.doi.org/10.1002/app.10372

[13] Katsuyuki Yokomizo, K., Banno, Y., Yoshikawa, T. and Kotaki, M. (2013) Effect of Molecular Weight and Molecular Weight Distribution on Weld-Line Interface in Injection-Molded Polypropylene. Polymer Engineering \& Science, 53, 2336-2344. http://dx.doi.org/10.1002/pen.23487

[14] Pistor, C. and Friedrich, K. (1997) Scratch and Indentation Tests on Polyoxymethylene (POM). Journal of Applied Polymer Science, 66, 1985-1996. http://dx.doi.org/10.1002/(SICI)1097-4628(19971205)66:10<1985::AID-APP15>3.0.CO;2-U

[15] Kody, R.S. and Martin, D.C. (1996) Quantitative Characterization of Surface Deformation in Polymer Composites Using Digital Image Analysis. Polymer Engineering \& Science, 36, 298-304. http://dx.doi.org/10.1002/pen.10416

[16] Dasari, A., Rohrmann, J. and Misra, R.D.K. (2002) Micro- and Nanoscale Evaluation of Scratch Damage in Poly(propylene)s. Macromolecular Materials and Engineering, 287, 889-903.

http://dx.doi.org/10.1002/mame.200290024 
[17] Chivatanasoontorn, V., Tsukise, S. and Kotaki, M. (2012) Surface Texture Effect on Scratch Behavior of Injection Molded Plastics. Polymer Engineering \& Science, 52, 1862-1867. http://dx.doi.org/10.1002/pen.23142

[18] Chivatanasoontorna, V., Yamada, K. and Kotaki, M. (2015) Highly Oriented Microstructures and Surface Mechanical Properties of Polypropylene (PP) Molded by Ultra-High Shear Rate. Polymer, 72, 104-112.

http://dx.doi.org/10.1016/j.polymer.2015.07.013

[19] Johannes, B., et al., Eds. (1999) Polymer Handbook. Wiley, New York.

[20] Kakudo, M. and Kasai, N. (1972) X-Ray Diffraction by Polymers. Elsevier, Amsterdam.

[21] Huo, H., Jiang, S. and An, L. (2004) Influence of Shear on Crystallization Behavior of the $\beta$ Phase in Isotactic Polypropylene with $\beta$-Nucleating Agent. Macromolecules, 37, 2478-2483. http://dx.doi.org/10.1021/ma0358531

[22] Nielsen, A.S, Batchelder, D.N. and Pyrz, R. (2002) Estimation of Crystallinity of Isotactic Polypropylene Using Raman Spectroscopy. Polymer, 43, 2671-2676. http://dx.doi.org/10.1016/S0032-3861(02)00053-8

[23] Kishima, Y. and Nishiyama, I. (2005) Characteristic Evaluation for Interface of Different Materials by SAICAS System. Journal of the Adhesion Society of Japan, 41, 234-241. http://dx.doi.org/10.11618/adhesion.41.234 